\title{
Effect of bismuth and bore content in glass system inhibitor on the corrosion behavior of mild steel in $1 \mathrm{M}$ hydrochloric acid solution
}

\author{
Azeddine Elbadaoui ${ }^{1}$, Mouhsine Galai ${ }^{2, *}$, Soumya Ferraa ${ }^{1}$, Hanane Barebita ${ }^{1}$, Mohammed Cherkaoui ${ }^{1}$ \\ and Taoufiq Guedira ${ }^{1}$ \\ ${ }^{1}$ Laboratory of Materials, Electrochemistry and Environment, Faculty of Science, \\ Ibn Tofail University, BP. 133-14000, Kénitra, Morocco \\ ${ }^{2}$ Laboratory of Materials Engineering and Environment: Modeling and Application, Faculty of Science, \\ Ibn Tofail University, BP. 133-14000, Kenitra, Morocco
}

\begin{abstract}
The influence of $(0.90-\mathrm{x}) \mathrm{Bi}_{2} \mathrm{O}_{3}-\mathrm{xB}_{2} \mathrm{O}_{3}-0.10\left(\mathrm{Ta}_{2} \mathrm{O}_{5}-\mathrm{Nb}_{2} \mathrm{O}_{5}\right)$ on the corrosion behavior of mild steel in $1 \mathrm{M}$ hydrochloric acid was studied. Electrochemical polarization and impedance spectroscopic methods measurements were used. The inhibition efficiency increases with S1 concentration to reach $79 \%$ at $150 \mathrm{ppm}$. Polarization curves show that our inhibitors. S1 is a cathodic inhibitor type. The increase in temperature leads to a decrease in the inhibition efficiency of the used inhibitor. The thermodynamic study showed that the film was formed at the steel surface by physisorption in the presence of inhibitor. Moreover, in this study, the results showed that the inhibition efficiencies depend on the $\mathrm{B}_{2} \mathrm{O}_{3}$ and $\mathrm{Bi}_{2} \mathrm{O}_{3}$ content in the glass. it is observed that the value at $50 \%$ of $\mathrm{B}_{2} \mathrm{O}_{3}$ in the glass provided better protection than the other content.
\end{abstract}

Keywords: Glass; corrosion inhibitor; mild Steel; 1.0 M Hydrochloric acid.

\section{Introduction}

The corrosion results from chemical or electrochemical action of an environment on the metals and alloys. The consequences are significant in various fields and in particular in the industry: production stoppage, replacement of corroded parts, accidents and risks of pollution are frequent events with sometimes substantial economic consequences ${ }^{1}$.

In terms of protection, corrosion inhibitors are a necessary means of protection against metal corrosion. An inhibitor is a chemical compound that is added in a small concentration to the medium to minimize the corrosion rate of the materials ${ }^{2-8}$.

The use of corrosion inhibitors is the best economical method to minimize mild steel corrosion. Heterocyclic compounds containing heteroatoms such as $\mathrm{N}, \mathrm{S}$ and Oxygen present a suitable inhibitor to stop la corrosion for mild steel in various acid medium, and many publications use these compounds 9-12.

For many industries that do the treatment of cooling, water circuits use different formulations to protect the pipes against corrosion. The majority of inhibitors used in these mediums are inorganic compounds ${ }^{13-16}$.
The objective of this study is to investigate the influence of inhibitor (glass) addition on the corrosion of mild steel in acidic medium $1.0 \mathrm{M} \mathrm{HCl}$.

\section{Experimental}

Synthesis of the vitreous phases of the system $\mathrm{Bi}_{2} \mathrm{O}_{3}-\mathrm{B}_{2} \mathrm{O}_{3}-\left(\mathrm{Ta}_{2} \mathrm{O}_{5}-\mathrm{Nb}_{2} \mathrm{O}_{5}\right)$

The vitreous phases of the system $\mathrm{Bi2O} 3-\mathrm{B} 2 \mathrm{O} 3-$ (Ta2O5-Nb2O5) are obtained by fusion of the stoichiometric mixtures of the starting products according to the reaction pathway: $(1-\mathrm{x}-\mathrm{y}) \mathrm{Bi} 2 \mathrm{O} 3+\mathrm{xB} 2 \mathrm{O} 3+\mathrm{y} / 2 \mathrm{Ta} 2 \mathrm{O} 5+\mathrm{y} / 2 \mathrm{Nb} 2 \mathrm{O} 5(1-\mathrm{x}-$ y) $\mathrm{Bi} 2 \mathrm{O} 3+\mathrm{xB} 2 \mathrm{O} 3+\mathrm{y} / 2 \mathrm{Ta} 2 \mathrm{O} 5+\mathrm{y} / 2 \mathrm{Nb} 2 \mathrm{O} 5$.

The reagents carefully are crushed in an agate mortar then introduced into alumina crucibles. First heat treatment was carried out at $350^{\circ} \mathrm{C}$ during one night followed by crushing; the temperature was increased by $50{ }^{\circ} \mathrm{C}$ in order to avoid the chemical losses by volatilization; followed by melting at $950^{\circ} \mathrm{C}$.

The reactional mixture is then brought up to a higher temperature at the melting point. The molten mixture is then soaked with the free air in a mould out of alumina heated beforehand with approximately $200^{\circ} \mathrm{C}$. 
The band between $1190-1240 \mathrm{~cm}^{-1}$ is allotted to the vibration of the final groupings $\mathrm{B}-\mathrm{O}$ - in units pyroborates ${ }^{17-19}$.

On the other hand, the line around $1270-1310 \mathrm{~cm}^{-1}$ is allotted to the asymmetrical mode of elongation $\mathrm{B}-\mathrm{O}$ in the unit's orthoborate $\left(\mathrm{BO}_{3}\right)$.

The progressive addition of $\mathrm{B}_{2} \mathrm{O}_{3}$ causes an increase in the intensity of the bands located towards $420-490,500-540,600-690 \mathrm{~cm}^{-1}$ and the reduction in the intensity of the band around $1190-1240 \mathrm{~cm}^{-1}$. The wide strip located around $980-1000 \mathrm{~cm}^{-1}$ is dominant.

Reduction in the intensity of line around 1190$1240 \mathrm{~cm}^{-1}$ assigned with the units pyroborates compared to that located towards $600-690 \mathrm{~cm}^{-1}$ relative with the métaborates are explained by the conversion of the units pyroborates into units métaborates.

However, the reduction in the intensity of the band allotted to the pyroborates compared to the full strip towards980-1000 $\mathrm{cm}^{-1}$ seems related to the conversion of the pyroborates into entities diborate.
This transformation is probably related to the increase in the rate of boron atoms in co-ordination number IV.

The band between $640-650 \mathrm{~cm}^{-1}$ corresponds to the vibration of connection $\mathrm{Ta}-\mathrm{O}$, and the band $870 \mathrm{~cm}^{-1}$ is allotted to the vibration of the connection Ta-O-Ta ${ }^{20}$.

In general, the band from 600 to $950 \mathrm{~cm}^{-1}$ of $\mathrm{Nb}-\mathrm{O}$ vibrations of elongation can be observed ${ }^{21}$. The close band IR $920 \mathrm{~cm}^{-1}$ is allotted to the mode of stretching of connections $\mathrm{Nb}$ - $\mathrm{O}$ while strongest nearly $620 \mathrm{~cm}^{-1}$ was allotted to the stretching of more than bridging connections $\mathrm{Nb}-\mathrm{O}-\mathrm{Nb}$ deformed in $\mathrm{NbO}$ octahedral ${ }^{22}$. In particular, in the area from 500 to $700 \mathrm{~cm}^{-1}$ area of vibrations of the valence of Ta$\mathrm{O}-\mathrm{Nb}$.

\section{Studies of glasses of compositions} $(0.90-x) \mathrm{Bi}_{2} \mathrm{O}_{3}-\mathrm{x} \mathrm{B}_{2} \mathrm{O}_{3}-0.10\left(\mathrm{Ta}_{2} \mathrm{O}_{5}-\mathrm{Nb}_{2} \mathrm{O}_{5}\right)$

Table 1 gives the molar fractions corresponds to the compositions $(0.90-\mathrm{x}) \quad \mathrm{Bi} 2 \mathrm{O} 3-\mathrm{xB} 2 \mathrm{O} 3$ 0.10 (Ta2O5-Nb2O5). Figure 1 represents the infrared spectra of these compositions. The frequencies and their attributions are consigned in Table 2.

Table1. Composition of the samples prepared within the system $(0.90-\mathrm{x}) \mathrm{Bi}_{2} \mathrm{O}_{3}-\mathrm{xB}_{2} \mathrm{O}_{3}-0.10\left(\mathrm{Ta}_{2} \mathrm{O}_{5}-\mathrm{Nb}_{2} \mathrm{O}_{5}\right)$.

\begin{tabular}{|l|l|l|}
\hline Sample. $\mathbf{N}^{\circ}$ & $\mathbf{0 . 9 5 - \mathbf { x }}$ & $\mathbf{x}$ \\
\hline $\mathbf{S}_{1}$ & 0.65 & 0.3 \\
\hline $\mathbf{S}_{\mathbf{2}}$ & 0.6 & 0.35 \\
\hline $\mathbf{S}_{3}$ & 0.55 & 0.4 \\
\hline $\mathbf{S}_{\mathbf{4}}$ & 0.5 & 0.45 \\
\hline $\mathbf{S 5}_{5}$ & 0.45 & 0.5 \\
\hline
\end{tabular}

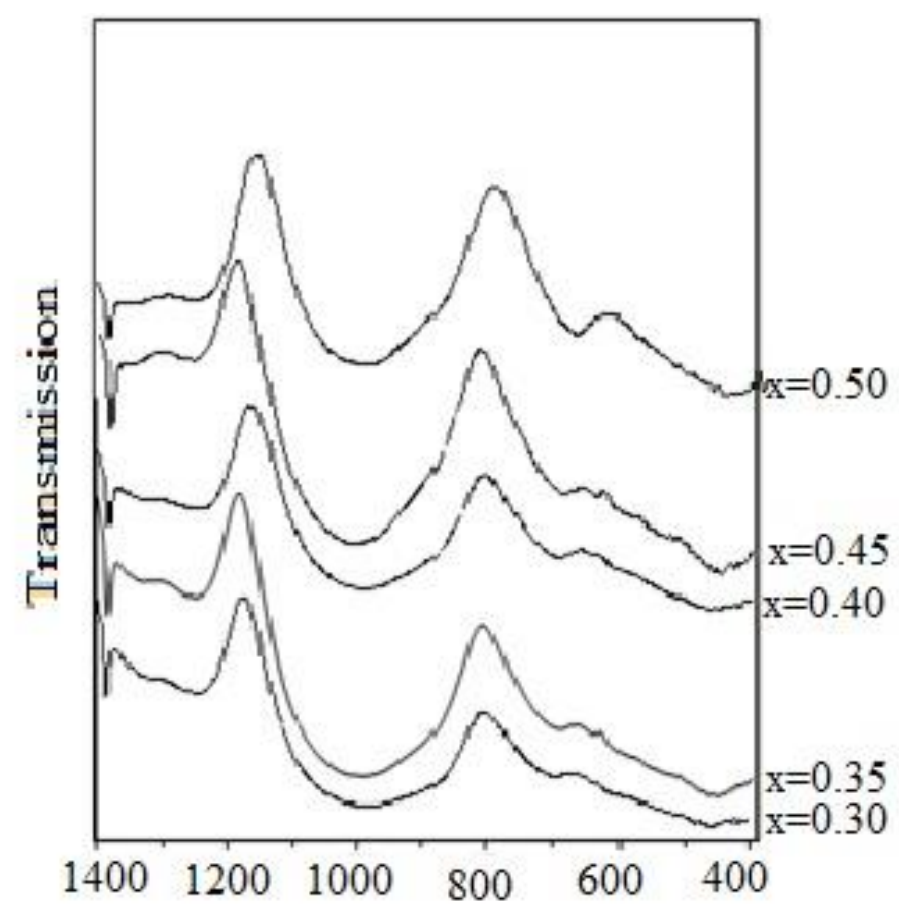

Figure 1. Spectra infra-red of glasses of compositions $(0.90-\mathrm{x}) \mathrm{Bi}_{2} \mathrm{O}_{3}-\mathrm{xB}_{2} \mathrm{O}_{3}-0.10\left(\mathrm{Ta}_{2} \mathrm{O}_{5}-\mathrm{Nb}_{2} \mathrm{O}_{5}\right)$. 
The analysis of the infra-red spectra of glasses of composition $\quad(0.90-\mathrm{x}) \quad \mathrm{Bi} 2 \mathrm{O} 3-\mathrm{x} \quad$ B2O3$0.1(\mathrm{Ta} 2 \mathrm{O} 5 \mathrm{Nb} 2 \mathrm{O} 5)$ shows that the substitution of bismuth by boron involves an increase in the intensities of the bands assigned with the units méthaborates $\mathrm{B}-\mathrm{O}-\mathrm{Bi}$ and $\mathrm{Bi}-\mathrm{O} \mathrm{Bi}$. We also observe the disappearance of the inversion of vas (BO) inBO3. We also notice a disappearance of the groupings orthoborates $\mathrm{BO}$. This can be explained by the conversion of the units orthoborates into unit métaborates.

The increase in the content of $\mathrm{Ta} 2 \mathrm{O} 5$ and $\mathrm{Nb} 2 \mathrm{O} 5$ in the system Bi2O3-B2O3- (Ta2O5-Nb2O5) involves

- A disappearance of the band corresponding to the groupings orthoborates $\mathrm{BO}_{3}$.

- A disappearance of the inversion of vas (BO) in $\mathrm{BO}_{3}$.

Table 2. Attributions of the infra-red frequencies of glasses of compositions (0.90-x) Bi2O3-x B2O3-0.10(Ta2O5-Nb2O5).

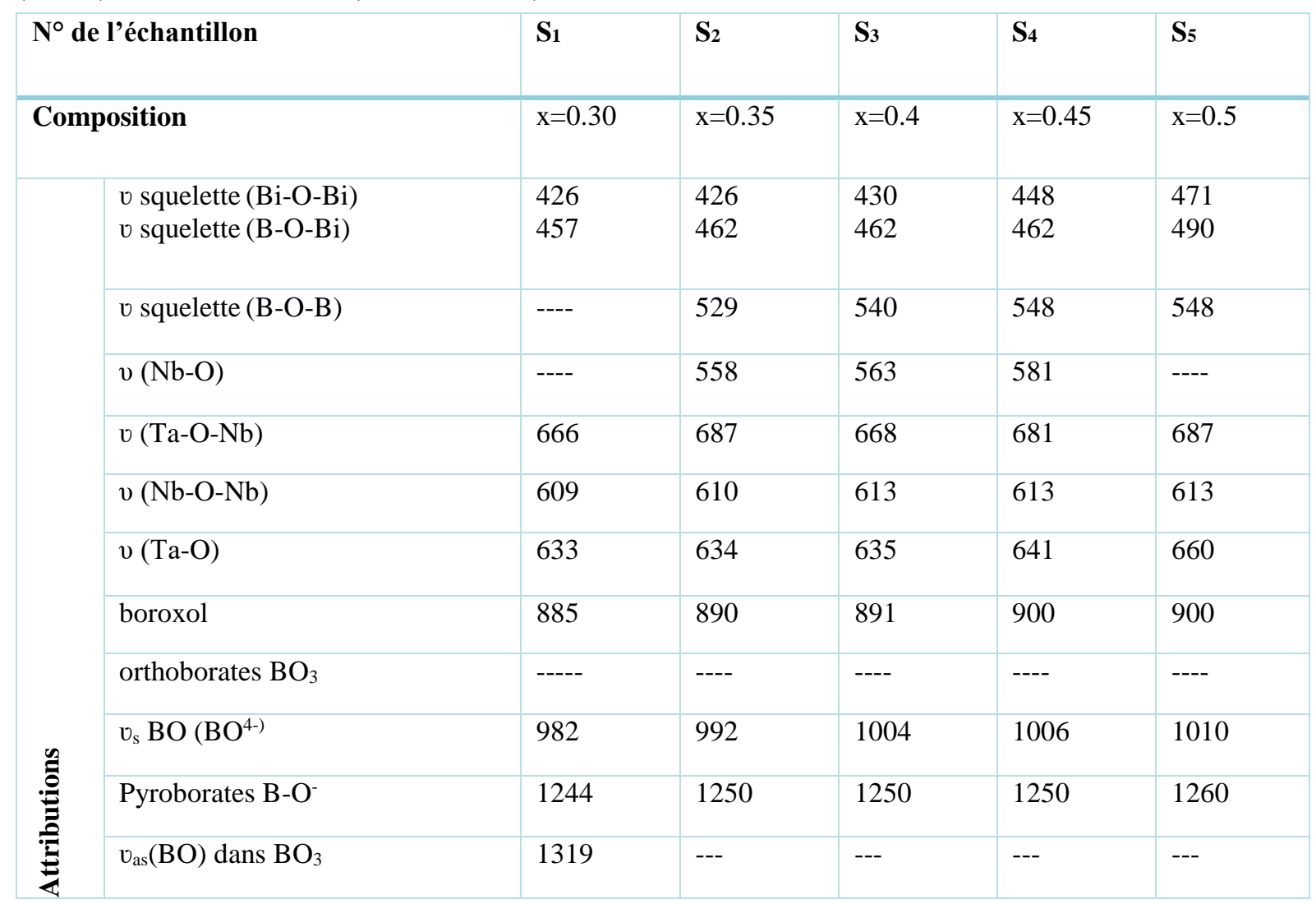

\section{Electrochemical measurements}

Before each experiment, the mild steel ((wt.\%) C $=0.21, \mathrm{Mn}=0.05, \mathrm{Si}=0.38, \mathrm{~S}=0.05, \mathrm{P}=0.09$, $\mathrm{Al}=0.01$ and the remaining iron) was polished using emery paper until 1200 grade. After this, it was decreased with ethanol, rinsed with distilled water and finally dried at room temperature. The aggressive solution $(1 \mathrm{M} \mathrm{HCl})$ was prepared by dilution of Analytical Grade $37 \% \mathrm{HCl}$ with distilled water. Inhibitors corrosion (Table 1) were added at their powder form to acid solution in the range of 100-300 ppm concentrations.

The potentiodynamic polarization curves were recorded by scanning the electrode equilibrium potential automatically from $\mathrm{E}_{\text {corr }}$ to the negative values and from $\mathrm{E}_{\text {corr }}$ to the positive values by using a potentiostat / Galvanostat PGZ 100 with scan rate equal $1 \mathrm{mV} / \mathrm{S}$ after $0.5 \mathrm{~h}$ of immersion in order to reach the state of equilibrium. The temperature of the solution was $298 \mathrm{~K}$. The electrochemical cell used had three electrodes. The reference electrode was a saturated calomel electrode (SCE). A platinum electrode was used as an auxiliary electrode. The working electrode was mild steel.

The extrapolation of Tafel lines calculates the electrochemical parameters. The effectiveness of corrosion inhibition is evaluated from values of corrosion current densities using relation (3):

$\eta_{\mathrm{PP}}=\frac{i_{\text {corr }}^{0}-i_{\text {corr }}}{i_{\text {corr }}^{0}} \times 100$

Where $\mathrm{i}_{\text {corr }}^{0}$ and $\mathrm{i}_{\text {corr }}$ are the values of corrosion current densities without and with inhibitor, respectively.

The electrochemical impedance spectroscopy was performed using a transfer function of the analyzer (VoltaLab PGZ100), with a low signal 
amplitude (10 $\mathrm{mV} \mathrm{rms),} \mathrm{over} \mathrm{a} \mathrm{frequency} \mathrm{range} \mathrm{from}$ $100 \mathrm{KHz}$ to $100 \mathrm{MHz}$ with ten points per decade. The SIE diagrams were carried out in the representation of Nyquist. The results were then analyzed via an equivalent electrical circuit using the Brockamp program $^{23}$.

The inhibition efficiency from the SIE is also calculated using the following equation:

$\eta_{\mathrm{EIS}}=\frac{R_{\mathrm{ct}}-R_{\mathrm{ct}}^{0}}{R_{\mathrm{ct}}} \times 100$

Where $R_{c t}{ }^{0}$ and $R_{c t}$ are the values of the charge transfer resistance in the absence and the presence of the inhibitor, respectively.

\section{Results and Discussion}

\section{Electrochemical Impedance Spectroscopy}

The corrosion study of mild steel in $1 \mathrm{M} \mathrm{HCl}$ solution with and without inhibitor was investigated by electrochemical impedance spectroscopy. The Nyquist representations of the behavior of mild steel in $1 \mathrm{M} \mathrm{HCl}$ with the addition of the various concentrations of S1 are presented in Figure 2.

From this Figure, all concentration of $\mathrm{S} 1$ does not have perfect semicircles due to the frequency dispersion. The loop diameter increased when the inhibitor concentration increase. The size of the highest loop is attributed to the adsorption of the inhibitor molecule ${ }^{24}$.

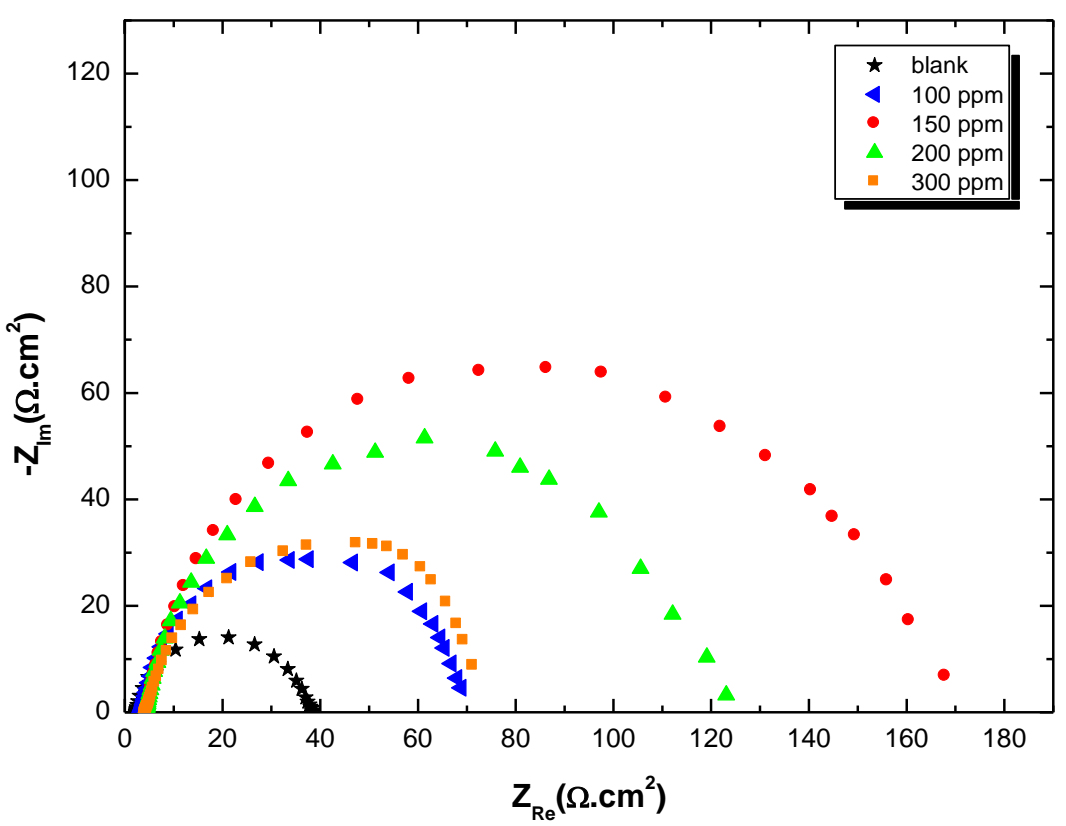

Figure 2. Nyquist diagrams obtained for mild steel in $1 \mathrm{M} \mathrm{HCl}$ that contain the different $\mathrm{S} 1$ concentrations after 30 min of immersion.

Table 3. Electrochemical impedance parameters in $\mathrm{HCl} 1 \mathrm{~mol} / \mathrm{L}$ at different $\mathrm{S} 1$ concentration.

\begin{tabular}{|l|l|l|l|}
\hline Cinh (M) of S1 & Rct $(\mathbf{o h m . c m})$ & $\mathbf{C d l}\left(\boldsymbol{\mu f} / \mathbf{c m}^{\mathbf{2}}\right)$ & $\mathbf{E \%}$ \\
\hline Blank & 35 & 284 & - \\
\hline $\mathbf{1 0 0 p p m}$ & 69 & 274 & 49 \\
\hline $\mathbf{1 5 0 p p m}$ & 168 & 124 & 79 \\
\hline $\mathbf{2 0 0 p p m}$ & 122 & 285 & 71 \\
\hline $\mathbf{3 0 0 p p m}$ & 73 & 261 & 52 \\
\hline
\end{tabular}

From Table 3, the values of Rt become more extensive with the decrease of the concentration of S1 and which holds a higher value at $150 \mathrm{ppm}$, which means a reduction in the rate of corrosion. The inhibitory efficacy $\mathrm{E}(\%)$, of this inhibitor, evolves in the same way as Rt and achieves a better inhibitory efficiency is $79 \%$.

The addition of the glass S1 decreases the value of the double-layer capacitance $\mathrm{Cdl}$ and passes from $284 \mu \mathrm{F} . \mathrm{cm}^{-2}$ for the white to $124 \mu \mathrm{F} . \mathrm{cm}^{-2}$. The decrease of the $\mathrm{Cdl}$ value can be attributed to the adsorption of the ions composition of the inhibitor on the surface of the steel ${ }^{25-27}$, in fact, more inhibitor adsorbs, the thickness of the film of the inhibitor increases and the double layer capacity decreases.

\section{Polarization curves}

The cathodic and anodic polarization curves of the working electrode in $1 \mathrm{M} \mathrm{HCl}$ in the absence and presence of various concentrations of $\mathrm{S} 1$ after prepolarization of the mild steel at its $\mathrm{E}_{\text {corr }}$ for 30 minutes are presented in Figure 3. The different 
electrochemical parameters extracted from these polarization curves, the corrosion current density (icorr), the corrosion potential (Ecorr), the cathodic Tafel slope $(\beta \mathrm{c})$ are associated in Table 4. Also, the cathodic Tafel slopes $(\beta c)$ calculated from Figure 3 is unchanged when the concentration of inhibitor increase. This observation shows that the activation controls hydrogen evolution, and the presence of inhibitor does not change the mechanism of the cathodic evolution reaction ${ }^{28-29}$.

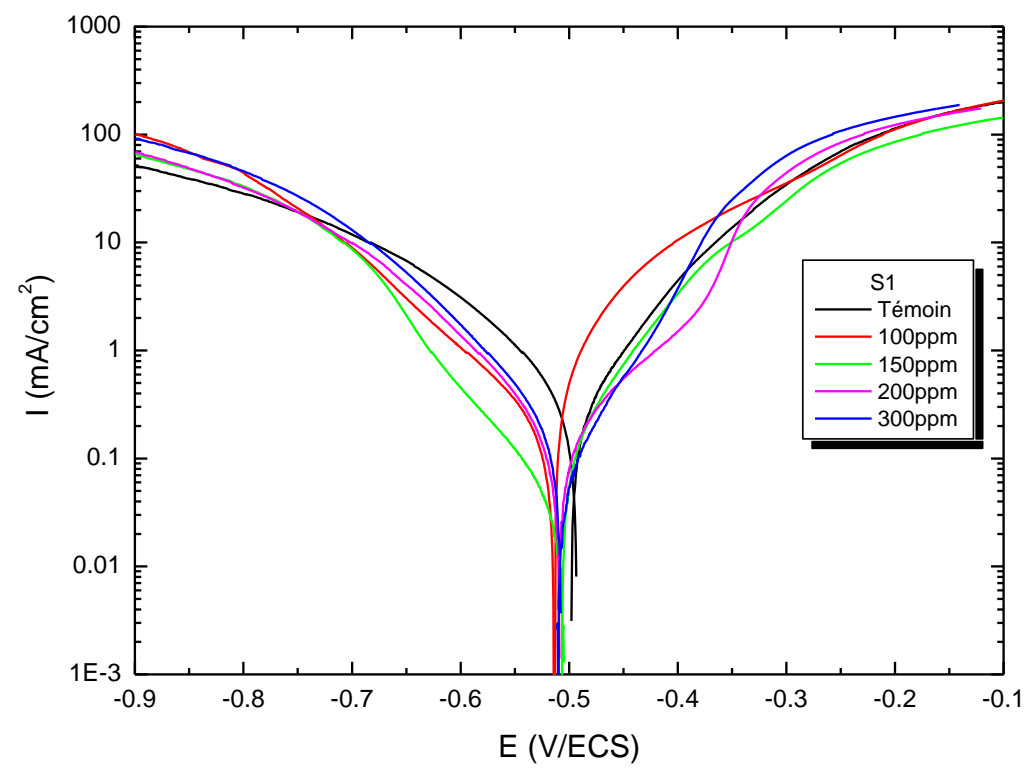

Figure 3. Polarization curves of the working electrode (mild steel) in $1 \mathrm{M}$ hydrochloric acid obtained at $25^{\circ} \mathrm{C}$ with the addition of the inhibitor at various concentrations of S1

Table 4. Potentiodynamic polarization parameters for the working electrode (mild steel) in $1 \mathrm{M}$ hydrochloric acid obtained at $25^{\circ} \mathrm{C}$ with the addition of the inhibitor at various concentrations of S1.

\begin{tabular}{|c|c|c|c|c|}
\hline $\mathbf{S 1}$ & $\mathbf{E}_{\mathbf{c o r r}}(\mathbf{m} \mathbf{V} / \mathbf{E C S})$ & $\mathbf{i}_{\mathbf{c o r r}}\left(\boldsymbol{\mu} \mathbf{A} / \mathbf{c m}^{2}\right)$ & $\boldsymbol{\beta c}(\mathbf{m v})$ & -92 \\
\hline Blank & -497 & 983 & -83 & - \\
\hline $\mathbf{1 0 0 p p m}$ & -507 & 474 & -87 & 79.5 \\
\hline $\mathbf{1 5 0 p p m}$ & -503 & 201 & -100 & 71 \\
\hline $\mathbf{2 0 0 p p m}$ & -512 & 281 & -86 & 54 \\
\hline
\end{tabular}

From Table 4, the inhibition efficiency increased with decreasing the concentration of $\mathrm{S} 1$ and this inhibitor affect the cathodic and anodic inhibition through adsorption on the working electrode surface by blockage of the active sites ${ }^{30}$. The corrosion potential Change slightly. According to Riggs et al. ${ }^{31}$ if the displacement in the potential of corrosion (i) is $>85 \mathrm{mV}$, the inhibitor acts as a cathodic or anodic type, (ii) if the displacement is $<85$, the inhibitor acts as mixed type. Effectively in our case, the displacement is lower than 85 , which can have classified our inhibitor $\mathrm{S} 1$ as a mixed type. Table 4 shows that the inhibition efficiency $\mathrm{E} \%$ increases when the concentration of the $\mathrm{S} 1$ decrease also $\mathrm{i}_{\text {corr }}$ decreases with when the concentration of $\mathrm{S} 1$ decrease. The higher inhibition efficiency is $79.5 \%$, and it obtained at $150 \mathrm{ppm}$ of $\mathrm{S} 1$ in $1 \mathrm{M} \mathrm{HCl}$.

\section{Effect of temperature}

Potentiodynamic

\section{measurements}

The influence of temperature on the inhibition of inhibitors, particularly the acidic environment, has been the subject of several articles; During pickling and descaling at high temperature, and in order to get rid of the corrosion products on the metallic installations, the inhibitors have the role of protecting the latter against acid attacks. Figures 4 and 5 show the polarization curves in $1 \mathrm{M} \mathrm{HCl}$ in the absence and the presence of $\mathrm{S} 1$ for the concentration of $150 \mathrm{ppm}$. The choice of concentration $150 \mathrm{ppm}$ is justified by the fact that at this concentration, the value of the efficiency is maximum. 


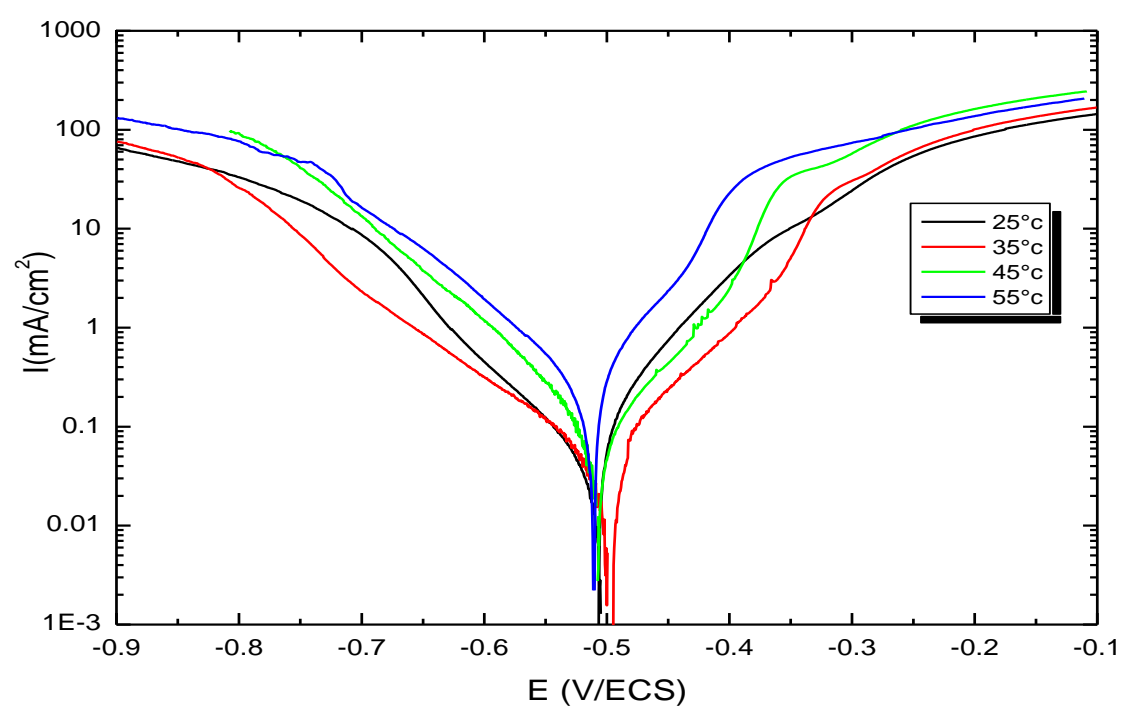

Figure 4. Polarization curves obtained for a working electrode in $1 \mathrm{M}$ of hydrochloric acid solution at different temperatures in the presence of $150 \mathrm{ppm}$ of $\mathrm{S} 1$.

Table 5. The electrochemical parameters for working electrode in $1 \mathrm{M}$ of a hydrochloric acid solution containing $150 \mathrm{ppm}$ of $\mathrm{S} 1$ at various temperature.

\begin{tabular}{|l|l|l|l|l|}
\hline & Ecorr $(\mathbf{m V} / \mathbf{E C S})$ & $\mathbf{i}_{\mathbf{c o r r}}\left(\boldsymbol{\mu} \mathbf{A} / \mathbf{c m}^{2}\right)$ & $\boldsymbol{\beta c}(\mathbf{m v})$ & $\mathbf{E \%}$ \\
\hline $\mathbf{2 5 \mathbf { C } ^ { \circ }}$ & -503 & 201 & -87 & 79.5 \\
\hline $\mathbf{3 5} \mathbf{C}^{\circ}$ & -491 & 368 & -82 & 77 \\
\hline $\mathbf{4 5} \mathbf{C}^{\circ}$ & -509 & 577 & -76 & 76 \\
\hline $\mathbf{5 5} \mathbf{C}^{\circ}$ & -511 & 752 & -83 & 75 \\
\hline
\end{tabular}

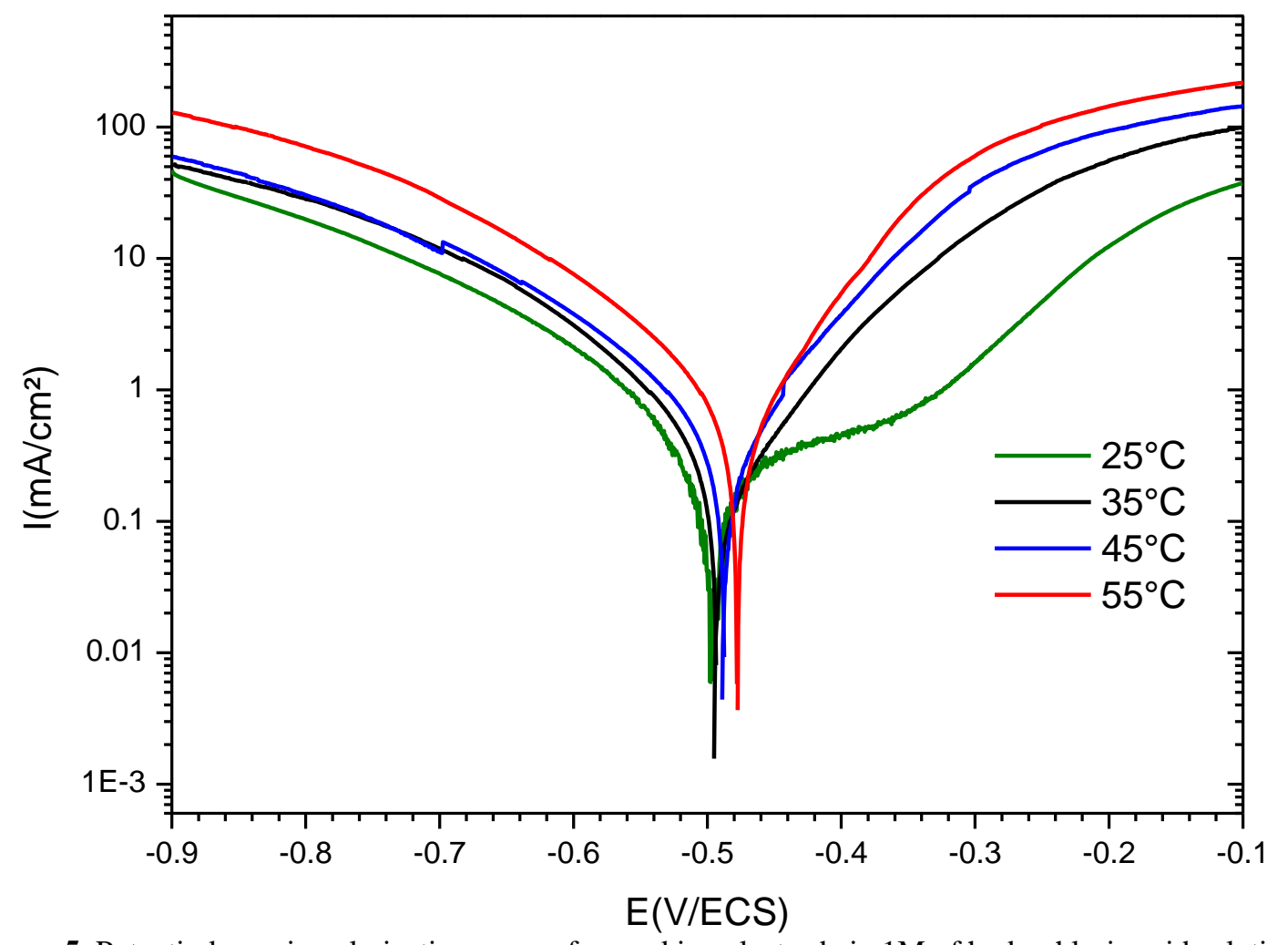

Figure 5. Potentiodynamic polarization curves for working electrode in $1 \mathrm{M}$ of hydrochloric acid solution at various temperatures. 
Table 6. the electrochemical parameters for working electrode in 1M of hydrochloric acid solution (Blank solution).

\begin{tabular}{|l|l|l|l|}
\hline & $\mathbf{E}_{\text {corr }}(\mathbf{m V} / \mathbf{E C S})$ & $\mathbf{i}_{\text {corr }}\left(\boldsymbol{\mu} \mathbf{A} / \mathbf{c m}^{2}\right)$ & $\beta \mathbf{~ c ~}(\mathbf{m v})$ \\
\hline $\mathbf{2 5 C} \mathbf{C}^{\circ}$ & -497 & 983 & -92 \\
\hline $\mathbf{3 5} \mathbf{C}^{\circ}$ & -491 & 1600 & -184 \\
\hline $\mathbf{4 5} \mathbf{C}^{\circ}$ & -475 & 2420 & -171 \\
\hline $\mathbf{5 5} \mathbf{C}^{\circ}$ & -465 & 3100 & -161 \\
\hline
\end{tabular}

From Table 6, the $\mathrm{S} 1$ inhibitor efficiencies are depended on the temperature. Also, the inhibitor efficiencies decrease with temperature; this observation can be attributed to the specific interaction between the Fe substrate surface and the inhibitor $^{32}$.

\section{Thermodynamic part}

For more details on the corrosion process, activation kinetic parameters such as activation energy (Ea), enthalpy $\left(\Delta \mathrm{H}^{*}\right)$ and entropy $\left.\Delta \mathrm{S}^{*}\right)$ were evaluated according to the Arrhenius law and the alternative formula of the following Arrhenius equation $^{33}$ :

$$
i_{\text {corr }}=K \exp \left(\frac{-E_{a}}{R T}\right)
$$

Where:

Ea: activation energy,

$\mathrm{K}$ : pre-exponential factor,

$\mathrm{R}$ : the universal gas constant

$\mathrm{T}$ : the absolute temperature presented in $\mathrm{K}$

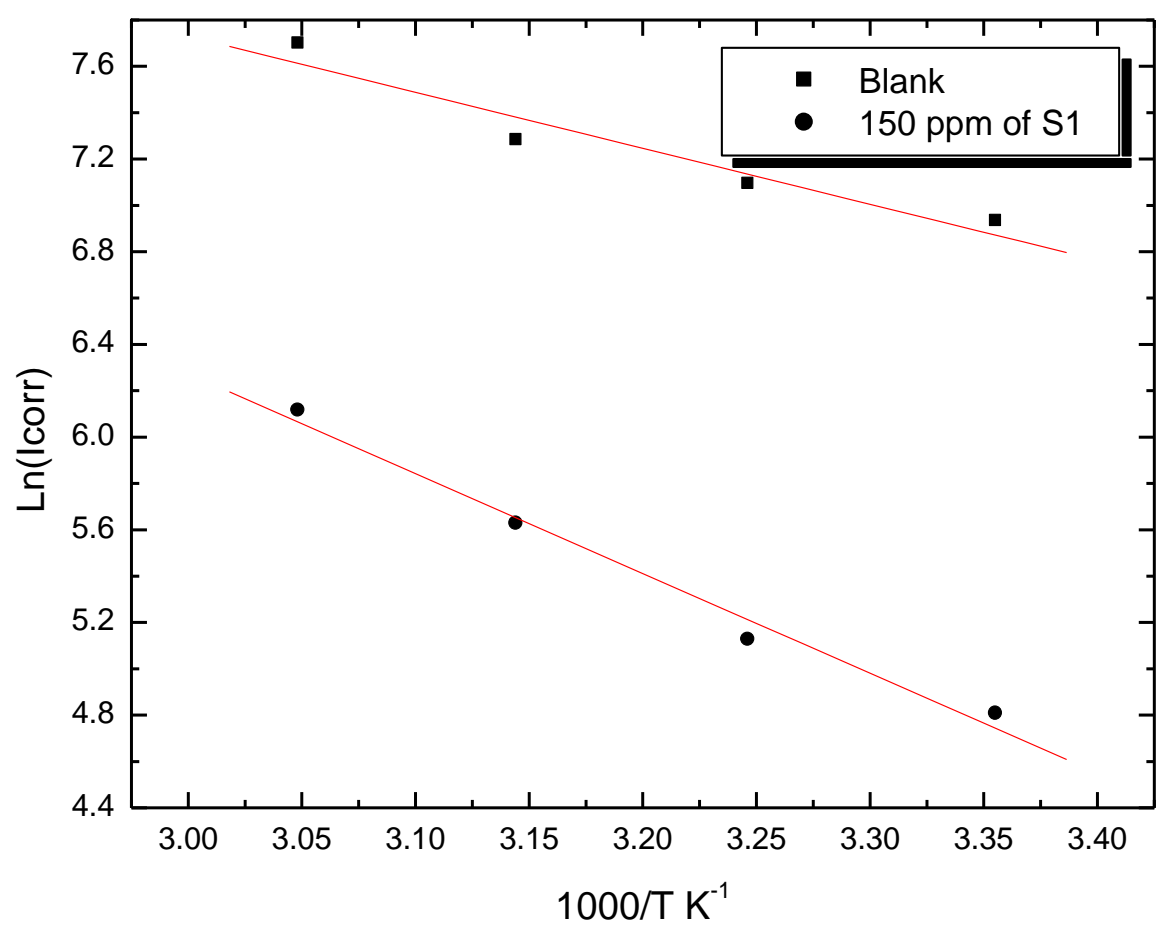

Figure 6. Arrhenius strains calculated from $\mathrm{i}_{\text {corr }}$ of the working electrode in $1 \mathrm{M}$ hydrochloric acid and for 150 ppm of $\mathrm{S} 1$.

The linear regression coefficients are close to the unit, indicating that the mild steel corrosion in $\mathrm{HCl}$ $1 \mathrm{M}$ can be calculated by using the Arrhenius model. From Table 7, the Ea of 150 ppm of S1 was higher than that of Blank solution. This increasing in Ea can interpret as physical adsorption. Effectively, a higher energy barrier for the corrosion process in the solution containing the inhibitor is involved with physical adsorption or weak chemical bonding between the compound molecule and the substrate surface ${ }^{34}$. Szauer et al. demonstrate that the higher value of Ea can be explained to a decrease in the adsorption processes of the inhibitor (glass) on the substrate surface when the temperature increase ${ }^{35}$.
The formula of the Arrhenius equation allows the determination of enthalpy and entropy according to the next equation:

$$
I \operatorname{corr}=\frac{k_{B} T}{h} \exp \left(\frac{\Delta S^{*}}{R T}\right) \exp \left(\frac{-\Delta H^{*}}{R T}\right)
$$

Where:

h: Planck's constant,

$\mathrm{K}_{\mathrm{B}}$ :is Boltzmann constant,

$\mathrm{R}$ : the universal gas constant,

$\Delta \mathrm{H}_{\mathrm{a}}^{*}$ : the enthalpy of the activation $\Delta \mathrm{S}_{\mathrm{a}}$ : the entropy of activation. 
Figure 7 illustrates the variation of $\ln$ icorr / T as a function of the inverse of the temperature for the acid solution and the concentration of $150 \mathrm{ppm}$ of $\mathrm{S} 1$. The straight lines obtained have a slope equal to $(-\Delta \mathrm{H} * / \mathrm{R})$ and an ordinate at the origin equal to $(\ln (\mathrm{R} / \mathrm{Nh})+\Delta \mathrm{S} * / \mathrm{R}) . \Delta \mathrm{H} *$ and $\Delta \mathrm{S} *$. The values of enthalpies $\Delta \mathrm{H} *$ and entropies and $\Delta \mathrm{S} *$ are given in Table 7.

From Table 7 , the $\Delta \mathrm{Ha}^{*}$ values for dissolution reaction of mild steel in $1.0 \mathrm{M} \mathrm{HCl}$ in the presence of $150 \mathrm{ppm}$ of $\mathrm{S} 1$ is higher than the blank solution (28 $\left.\mathrm{kJ} \mathrm{mol}^{-1}\right)$. The positive signs of $\Delta \mathrm{Ha}^{*}$ values reflect the endothermic nature of the $\mathrm{Fe}$ substrate dissolution mechanism; this dissolution is slow ${ }^{36}$. Also, the values of Ea is higher than the s value of $\Delta \mathrm{Ha}^{*}$ indicating that the corrosion must be associated to a gaseous reaction, the hydrogen evolution reaction, involved with a decrease in the total reaction volume ${ }^{37}$.

Also, the Table 7 shows that the $\Delta \mathrm{S}^{*}$ value increase in the presence of inhibitor compared to the uninhibited solution, which means an increase in disorder occurs during the transition from reactant to the activated complex during the corrosion mechanism $^{38-39}$.

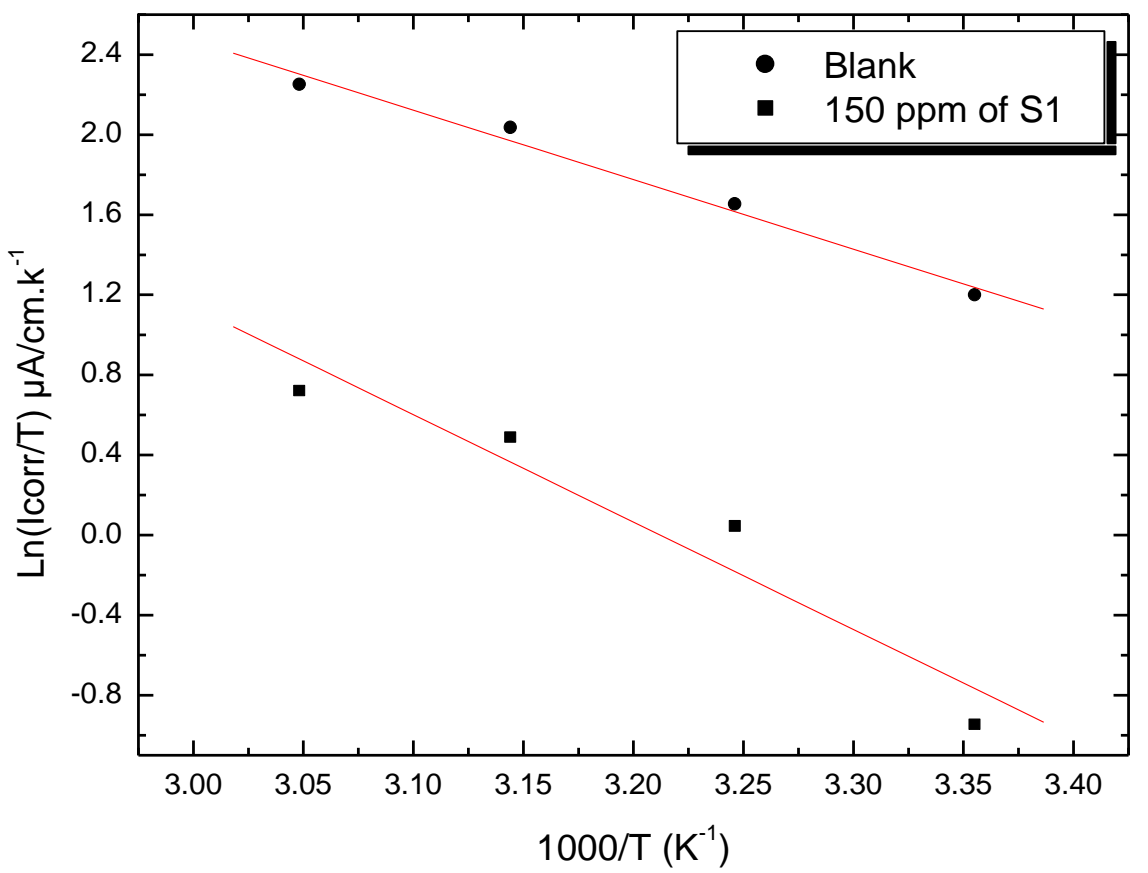

Figure 7. Transition Arrhenius plots for mild steel in $1 \mathrm{M}$ hydrochloric solution in the absence and the presence of $150 \mathrm{ppm}$ of $\mathrm{S} 1$.

Table 7. Activation parameters for working electrode corrosion in $1 \mathrm{M}$ of the hydrochloric solution in the absence and the presence of $150 \mathrm{ppm}$ of $\mathrm{S} 1$.

\begin{tabular}{|l|l|l|l|}
\hline & EA KJ/mol & AH KJ/mol & $\Delta \mathbf{S ~ K J / m o l ~}$ \\
\hline Blank & 31.5 & 28 & -107 \\
\hline $\mathbf{1 5 0} \mathbf{~ p p m ~ S 1 ~}$ & 36 & 33.3 & -50 \\
\hline
\end{tabular}

\section{Effect of Bore content in the glass}

The corrosion behavior of mild steel in $1 \mathrm{M}$ of hydrochloric solution for different compositions of glasses in the system (0.95-x) Bi2O3-x B2O3-0.05at $150 \mathrm{ppm}$, was investigated using EIS method at $25^{\circ} \mathrm{C}$ after $0.5 \mathrm{~h}$ of immersion at corrosion potential (Fig. 8). The effect of bore (B) and bismuth (Bi) on the corrosion resistance of mild steel in $1 \mathrm{M} \mathrm{HCl}$ solution was investigated. in other studies, the presence of both increase the resistance of transfer of charge Rct according to ${ }^{40}$.in this study we are increasing the concentration of bore and bismuth comparing with former study, moreover the percentage of $\mathrm{Ta}$ and $\mathrm{Nb}$ are also increasing in these glasses systems.
It is noticed from these plots presented in Figure 8 that the impedance of mild steel in uninhibited solution (Blank solution) has changed after the addition of each inhibitor. The higher is obtained when the glass contains a high content of $\mathrm{B}_{2} \mathrm{O} 3$. The electrochemical parameters and the inhibition efficiencies values are regrouped in Table 8 for all percentage of $\mathrm{B}_{2} \mathrm{O}_{3}$, the addition of glasses in the blank solution the charge transfer resistance increase. This change can be attributed to the decrease in the local dielectric constant, and an increase in the thickness of the electrical double layer suggests that the glasses molecules by adsorption at the metal/solution interface ${ }^{41}$. 


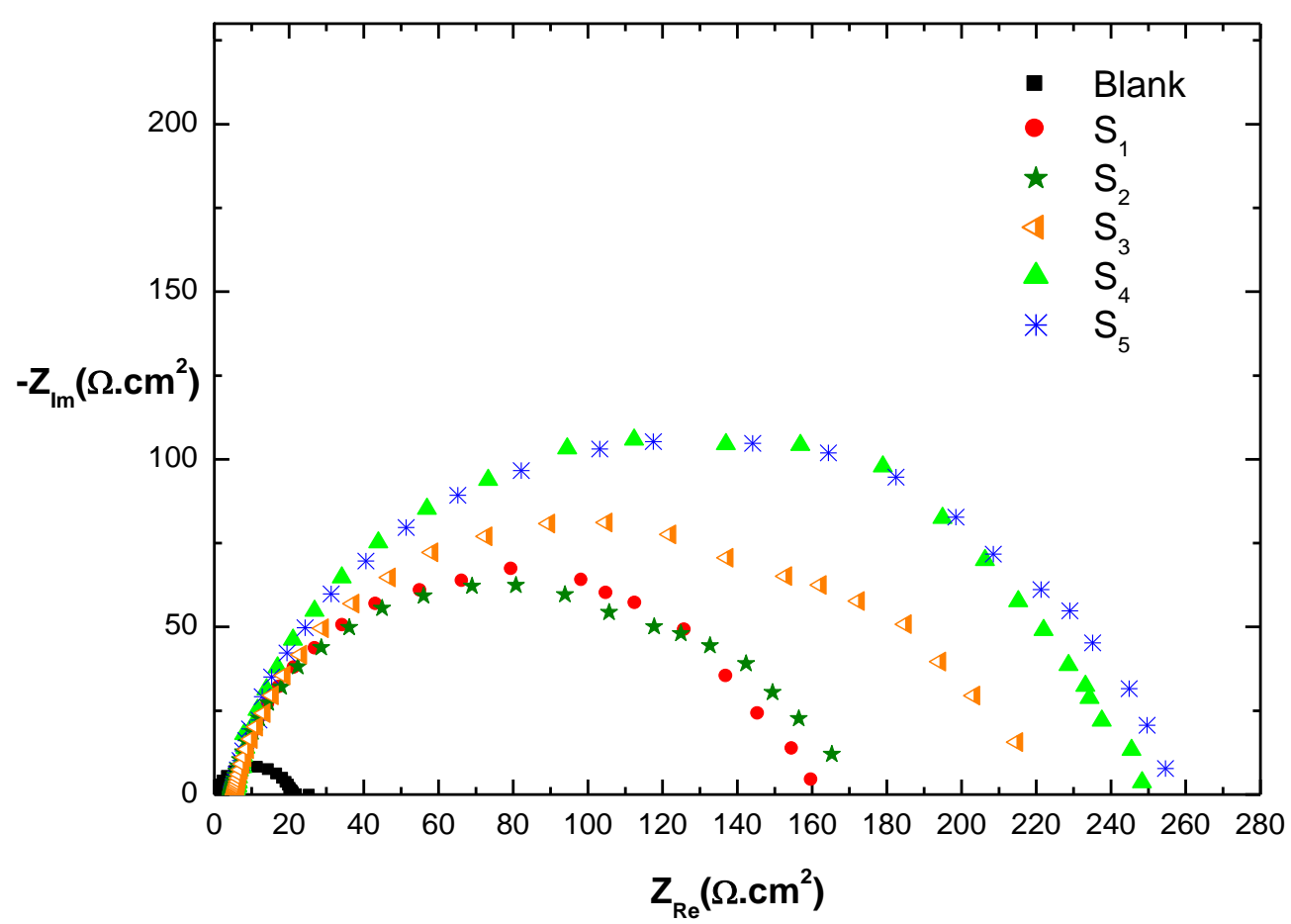

Figure 8. Impedance diagram of working electrode recoded in $1 \mathrm{M} \mathrm{HCl}$ containing $150 \mathrm{ppm}$ of each $(0.90-\mathrm{x})$ $\mathrm{Bi}_{2} \mathrm{O}_{3}-\mathrm{x} \mathrm{B}_{2} \mathrm{O}_{3}-0.10-\left(\mathrm{Ta}_{2} \mathrm{O}_{5}-\mathrm{Nb}_{2} \mathrm{O}_{5}\right)$ at corrosion potential (x varied from $0.3 \%$ to $0.5 \%$ ).

Table 8. Electrochemical parameters obtained from the Nyquist plots representation for mild steel in $1 \mathrm{M} \mathrm{HCl}$ containing 150 ppm of $(0.90-x) \mathrm{Bi}_{2} \mathrm{O}_{3}-\mathrm{x} \mathrm{B}_{2} \mathrm{O}_{3}-0.10-\left(\mathrm{Ta}_{2} \mathrm{O}_{5}-\mathrm{Nb}_{2} \mathrm{O}_{5}\right)$. glass system ( $\mathrm{x}$ varied from $0.3 \%$ to $0.5 \%$ ).

\begin{tabular}{|l|l|l|l|}
\hline Cinh $(\mathbf{M})$ of BA6 & Rct $\left(\mathbf{o h m . c m} \mathbf{c}^{\mathbf{2}}\right)$ & $\mathbf{C d l}\left(\boldsymbol{\mu f} / \mathbf{c m}^{2}\right)$ & $\mathbf{E \%}$ \\
\hline blank & 35 & 284 & - \\
\hline s1 & 168 & 124 & 79 \\
\hline s2 & 170 & 111 & 79.5 \\
\hline $\mathbf{s 3}$ & 222 & 105 & 84 \\
\hline $\mathbf{s 4}$ & 251 & 99 & 86 \\
\hline $\mathbf{s 5}$ & 258 & 84 & 86.5 \\
\hline
\end{tabular}

The inhibition efficiency increases with $\mathrm{B}_{2} \mathrm{O}_{3}$ content and reaching a higher value at $50 \%$ of $\mathrm{B}_{2} \mathrm{O}_{3}$. The adsorption of these products on mild steel displaces the water molecule and other ions already adsorbed $^{42}$.

\section{Conclusion}

The glasses $(0.90-\mathrm{x}) \quad \mathrm{Bi} 2 \mathrm{O} 3-\mathrm{x} \quad \mathrm{B} 2 \mathrm{O} 3-$ $0.10(\mathrm{Ta} 2 \mathrm{O} 5-\mathrm{Nb} 2 \mathrm{O} 5)$ system were prepared and then characterized by X-ray diffraction; this allowed the delimitation of the vitreous zone. The inhibition of the mild steel corrosion in $1 \mathrm{M} \mathrm{HCl}$ acid medium by this system was studied by polarization curve and electrochemical impedance spectroscopy. The obtained results showed a significant decrease in the corrosion current and an increase in charge transfer resistance when the compounds were added to the corrosive solution. This inhibition depends on the composition of the vitreous phase. The inhibitory efficiency reaches $79 \%$ at a concentration of $150 \mathrm{ppm}$ for the $\mathrm{S} 1$ additive. The system acts primarily as a cathodic inhibitor by forming a stable film on the steel surface. The thermodynamic study showed that this film was formed by physisorption. Moreover, the inhibition efficiency increases with $\mathrm{B}_{2} \mathrm{O}_{3}$ content, reaching a maximum value at $50 \%$ of $\mathrm{B}_{2} \mathrm{O}_{3}$ in our case is the inhibitor S5.

\section{References}

1- J. Zhang, J. Liu, W. Yu, Y. Yan, L. You,

L. Liu, Corrosion. Sci., 2010, 52, 2059-2065.

2- M. Iannuzzi, G.S. Frankel, Corrosion., 2007, 63, 672-688.

3- A. Singh, S. K. Shukla, M. Singh, M. A. Quraishi, Mater. Chem. Phys., 2011, 129, 68-76

4- S. K. Shukla, M. A.Quraishi, Mater.Chem.Phys., 2010, 120, 142-147.

5- S. K. Shukla, A. K.Singh, I. Ahamad, M. A. Quraishi, Mater. Lett., 2009, 63, 819-822.

6- S. K. Shukla, M. A. Quraishi, Corros. Sci., 2009, 51, 1007-1011.

7- S. K. Shukla, M. A. Quraishi, R. Prakash, Corros. Sci., 2008, 50, 2867-2872.

8- M. W. Ranney, Inhibitors Manufacture and Technology; 1976, Noyes Data Corp: NJ, 
9- F. Bentiss, M. Traisnel, H. Vezin, H.F. Hildebrand, M. Lagren, Corros.Sci., 2004, 46, 2781-2792

10- R. A. Prabhu, T. V. Venkatesha, A. V. Shanbhag, B. M. Praveen, G. M. Kulkarni, R. G. Kalkhambkar, Mater. Chem. Phys., 2008, 108, 283.

11- P. Lowmunkhong, D. Ungthararak, P. Sutthivaiyakit, Corros. Sci.,2010, 52, 30-36.

12- F. Bentiss, C. Jama, B. Mernari, H. E. Attari, L. E. Kadi, M. Lebrini, M. Traisnel, M. Lagrenee, Corros. Sci., 2009, 51, 1628-1635.

13- M. R. Ali, C.M. Mustafa, M. Habib, J. Sci. Res., 2009, 1, 82-91.

14- M. Iannuzzi, G.S. Frankel, Corrosion, 2007, 63, 672-688.

15- G.H. Nancollas, Corrosion, 1983, 39, 77-82.

16- G.H. Nancollas, Corrosion, 1983, 39, 77-82.

17- M. Belfaquir, Guedira, S. D. Elyoubi, J.L. Rehspringer, Synthèse et caractérisation des phases du système ternaire $\mathrm{Bi}_{2} \mathrm{O}_{3}-\mathrm{P}_{2} \mathrm{O}_{5}-\mathrm{B}_{2} \mathrm{O}_{3}$, Ann. Chim. SciencesMatériaux , 2005, 30, 27-35.

18- M. Belfaquir, T.Guedira, S. D. Elyoubi, J.L. Rehspringer, Etude structurale des verres borate du système $\mathrm{Bi}_{2} \mathrm{O}_{3}-\mathrm{P}_{2} \mathrm{O}_{5}-\mathrm{B}_{2} \mathrm{O}_{3}$, Sciences Lib Editions Mersenne, 2013, 5.

19- M. Belfaquir, T. Guedira, S. D. Elyoubi, J.L. Rehspringer, Etude vibrationnelle et électrique des verres de phosphates isolés dans le système $\mathrm{Bi}_{2} \mathrm{O}_{3}-\mathrm{P}_{2} \mathrm{O}_{5}-\mathrm{B}_{2} \mathrm{O}_{3}$, Sciences Lib Editions Mersenne, 2013, 5.

20- 20. B.B. Meera, A.K. Sppd, N. Chandradhas, J. Ramakrishna, Journal of Non-Crystalline Solids, 1990, 12, 126, 224.

21- A. Pawlicka, M. Atik, M.A. Aegerter .Thin Solid Films, 1997, 301, 236

22- T. Armaroli, G. Busca, C. Carlini, M. Giuttari, A.M.R. Galletti, G. Sbrana, J. Mol. Catal. A,2000, 151, 233.

23- M. Galai, J. choucri, Y. Hassani, H. Benqlilou, I. Mansouri, B. Ouaki, M. Ebn Touhami, C. Monticelli, F. Zucchi, Chemical Data Collections, 2019, 19, 100171.

24- S.K. Shukla, M.A. Quraishi, Corros. Sci., 2009, doi:10.1016/j.corros.2009.05.020.

25- M.G. Hosseini, M. Ehteshamzadeh, T. Shahrabi, Electrochem. Acta, 2007, 52, 3680-3685

26- S. Murlidharan, K.L.N. Phani, S. Pitchumani, S. Ravichandran, J. Electrochem.Soc, 1995, 142, 1478-1483

27- F. Bentiss, M. Traisnel, M. Lagrenee, Corros. Sci, 2000, 42, 127-146.

28- B.G. Ateya, M.B.A. El-Khair, I.A. AbdelHamed, Corros. Sci, 1976, 15, 163- 169

29- W. Li, Q. He, S. Zhang, C. Pei, B. Hou, J. Appl. Electrochem, 2008,38, 289-295.
30- M. Galai, M. El Faydy, Y. El Kacimi, K. Dahmani, K. Alaoui, R. Touir, B. Lakhrissib and M. Ebn Touhami "Synthesis,

Characterization and Anti-Corrosion Properties of Novel Quinolinol on C-steel in a Molar Hydrochloric Acid Solution." Portugaliae Electrochimica Acta, 2017, 35(4), 233-251.

31- O.L. Riggs, Jr., Corrosion Inhibition, 1973, second ed., C.C. Nathan, Houston, TX.

32- I. A. Ammar, F. M. El Khorafi, Werkst. Korros, 1973, 24, 702.

33- K. Dahmani, M. Galai, M. Cherkaoui, A. El hasnaoui, A. El Hessni. J. Mater. Environ. Sci.2017, 8, 1676-1689.

34- A. Popova, E. Sokolova, S. Raicheva, M. Christov, AC and DC study of the temperature effect on mild steel corrosion in acid media in the presence of benzimidazole derivatives." Corrosion Science, 2003, 45, 33-58.

35- T. Szauer, A. Brand, Adsorption of oleates of various amines on iron in acidic solution, Electrochim. Acta, 1981, 26, 1253-1256.

36- H.Gerengi, K. Darowicki, G. Bereket, P. Slepski, Evaluation of corrosion inhibition of brass-118 in artificial seawater by benzotriazole using dynamic EIS, Corros. Sci, 2009, 51, 2573-2579.

37- L. Saqalli, M. Galai, N. Gharda, M. Sahrane, R. Ghailane, M. Ebn Touhami, Y. Pereslucchese, A. Souizi, N. Habbadi. Int. J. Electrochem. Sci., 2018,13, 5096-5119.

38- A.K. Singh, S.K. Shukla, M. Singh, M.A. Quraishi, Inhibitive effect of ceftazidime on corrosion of mild steel in hydrochloric acid solution, Mater. Chem. Phys, 2011,129,68-76.

39- M. Galai, M. Rbaa, Y. El Kacimi, M.Ouakki, N. Dkhirech, R. Touir, B. Lakhrissi and M. EbnTouhami, Anal. Bioanal. Electrochem, 2017, 9, 80-101

40- A. Elbadaoui, M. Galai, M. Cherkaoui, T. Guedira. Preparation and characterization of a vitreous phase and application as a corrosion inhibitor in acidic medium. Der Pharma Chemica, 2016, 8, 214-221.

41- M. Galai, M. El Gouri, O. Dagdag, Y. El Kacimi, A. Elharfi, M. Ebn Touhami. New Hexa Propylene Glycol Cyclotiphosphazene As Efficient Organic Inhibitor of Carbon Steel Corrosion in Hydrochloric Acid Medium. J. Mater. Environ. Sci, 2016, 7, 1562-1575.

42- A. Majjane, D. Rair, A. Chahine, M. Et-tabirou, M. Ebn Touhami, R. Touir, Preparation and characterization of a new glass system inhibitor for mild steel corrosion in hydrochloric solution. Corrosion Science, 2012, 60, 98-103. 